\title{
OS INSTITUTOS FEDERAIS DE EDUCAÇÃO, CIÊNCIA E TECNOLOGIA COMO VETORES DE DESENVOLVIMENTO LOCAL E REGIONAL
}

\author{
Mauro Sergio Pinheiro dos Santos de Souza* \\ Instituto Brasileiro de Geografia e Estatística
}

Resumo: 0 Estado brasileiro, desde 2005 e a partir da revalorização e ressignificação da educação profissional no País, estabeleceu uma política pública nacional de Educação que visou expandir e desconcentrar a rede federal ensino profissional. Essas transformações estão intrinsecamente relacionadas às mudanças operadas no sistema produtivo de modo geral que tem repercutido no modo de atuação do Estado ao se engajar os territórios, nas escalas subnacionais, para o desenvolvimento nacional e a competição econômica. É com base nessas premissas que se estabeleceu a expansão e a desconcentração da rede federal de ensino profissional: a educação profissional para a elevação da educação da população atendida e na produção de inovações, a partir da prospeç̧ão das potencialidades locais e regionais. Evidencia-se nesse programa de expansão a proeminência do território como guia para orientar as atividades acadêmicas da nova figura institucional da rede criada em 2008: os Institutos Federais de Educação, Ciência e Tecnologia. Tais instituições foram criadas com o fito de propiciar às diferentes localidades do país instrumentos de fortalecimento do desenvolvimento, ao guarnecer essas localidades com um corpo docente qualificado, além de uma infraestrutura institucional capaz de contribuir com esse objetivo. Apresentam-se, por isso, exemplos da importância da atuação dos Institutos Federais nas escalas local e regional, propondo-se uma reflexão do papel desempenhado por essas instituições. Na medida em que o País pena com a lacuna educacional de sua população, o papel da União no sistema educativo deve ser reforçado, pois implica novas oportunidades para as localidades atendidas. Palavras-chave: Desconcentração, Rede Federal de Educação, Ensino Profissional, Desenvolvimento Local e Regional.

\section{Federal Institutes of Education, Science and Technology as vectors to local and regional development}

Abstract: Federal Government, since 2005 and based on the revalorization and re-signification of vocational education in the country, established a national public education policy that aimed to expand and decentralize the federal vocational education network. These transformations are intrinsically related to the changes in the productive system in general that have had repercussions on the State's way of engaging the territories, at the subnational scales, for national development and economic competition. It is on the basis of these premises that the expansion and deconcentration of the federal network of vocational education was established: vocational education to raise the education of the population and in the production of innovations, from the prospection of local and regional potentialities. In this program of expansion, the prominence of the territory as a guide to orient academic activities of the new institutional figure of the network created in 2008: the Federal Institutes of Education, Science and Technology. These institutions were created with the purpose of providing the different localities of the country ways to strengthen development, by providing these locations with a qualified teaching staff, as well as an institutional infrastructure capable of contributing to this goal. Therefore, examples of the importance of the action of the Federal Institutes at the local and regional scales are presented, and a reflection on the role played by these institutions is proposed. To the extent that the country endures an educational gap of its population, the role of the Union in the education system should be strengthened, as it implies new opportunities for the places served.

Keywords: Deconcentration, Education Federal network, Vocational Education, Local and Regional Development.

\section{INSTITUTOS FEDERALES DE EDUCACIÓN, CIENCIA Y TECNOLOGÍA COMO VECTORES DE DESARROLLO LOCAL Y REGIONAL}

Resumen: El Estado brasileño, desde 2005 y después de la revaluación y resignificación de la educación profesional en el país, ha establecido una política nacional de educación pública que tenía como objetivo expandir y desconcentrar la red federal de educación profesional. Esas transformaciones están intrínsecamente relacionadas con cambios en el sistema productivo en general que han tenido repercusiones en el modo de acción del Estado al abarcar territorios, en escalas subnacionales, para el desarrollo nacional y la competencia económica. Se basa en estas premisas que se estableció la expansión y desconcentración de la red federal de educación vocacional: educación profesional para aumentar la educación de la población atendida y la producción de innovaciones, basadas en la prospección de las potencialidades locales y regionales. En este programa de expansión, la prominencia del territorio es evidente como una guía para guiar las actividades académicas de la nueva figura institucional de la red creada en 2008: los Institutos Federales de Educación, Ciencia y Tecnología. Dichas instituciones se crearon con el objetivo de proporcionar a diferentes regiones del país herramientas para fortalecer el desarrollo, proporcionando a estas ubicaciones un personal docente calificado, además de una infraestructura institucional capaz de contribuir a este objetivo. Por lo tanto, se presentan ejemplos de la importancia del desempeño de los Institutos Federales a escala local y regional, proponiendo una reflexión sobre el papel desempeñado por estas instituciones. En la medida en que el país sufre la brecha educativa de su población, debe reforzarse el papel de la Unión en el sistema educativo, ya que implica nuevas oportunidades para los lugares atendidos.

Palabras-clave: Desconcentración, Red Federal de Educación, Educación Profesional, Desarrollo Local y Regional. 
Introdução

A expansão e desconcentração da rede federal de ensino profissional, desde 2005, foi concebida como um dos vetores estratégicos da política pública de Educação do Governo Federal para o desenvolvimento local e regional no País, conjugada à formação de profissionais qualificados para atender às especializações e características da economia local e regional. Assim considerada, a desconcentração da rede possibilitaria que as instituições federais de ensino se tornassem estratégicas para o desenvolvimento territorial, na medida em que propiciariam novas possibilidades à comunidade local e regional.

De modo geral, o desenvolvimento econômico e social do Brasil pena com a sofrível lacuna educacional de sua população e com a baixa capacidade produtiva de inovações técnicas e tecnológicas, ainda marcadamente produzidas no âmbito universitário. Os desafios impostos ao desenvolvimento do território nacional devem, por isso, buscar sanar algumas fraquezas com as quais se tem deparado, entre elas, a educação e a capacidade de inovar da economia. A carência da educação de qualidade e a baixa produção de inovações se refletem num quadro mais amplo, em que está em jogo a capacidade de fortalecer a geração de riqueza dos municípios, dos estados, e, no conjunto, do País.

As desigualdades sociais e econômicas em território nacional refletem esse problema, uma vez que as instituições de ensino com maior tradição e capacidade de gerar inovações se localizam, historicamente, em poucas áreas do território. Nessa perspectiva, a Constituição de 1988 estabeleceu aos entes federados as respectivas responsabilidades no que se refere à promoção da educação. Em vista disso, o Governo Federal deve ter seu papel salientado, uma vez que, além de regulador do sistema nacional de educação, é mantenedor da rede federal de ensino profissional e superior (ABRUCIO, 2010).

Por outro lado, são poucos os estudos sobre o impacto do federalismo no funcionamento e nos resultados da educação do País (ABRUCIO, 2010, p. 39). Abrucio (2010) sustenta que a questão da educação nacional e a delegação de responsabilidades às escalas subnacionais não era consenso entre os especialistas da área. Não havia convergência sobre o formato que a descentralização deveria assumir. Para os defensores da descentralização o argumento, geralmente, calcava-se no cunho participativo que ela deveria assumir. Do outro lado, argumentava-se que a visão meramente municipalista não considerava as desigualdades regionais que marcam o País.

Para Abrucio (2010, p. 60), a Carta Magna conseguiu equilibrar a questão da partilha de competência da edu- cação entre os entes federativos. Houve a divisão das competências mais descentralizadoras na execução dos serviços, ao conferir um peso importante ao município. Mecanismos de transferência de recursos e a adoção de uma gestão democrática local garantiriam o controle social e evitariam a oligarquização do municipalismo. 0 receio maior residia, porém, na descentralização centrífuga, que seria problemática num País tão desigual.

Desse contexto emergiu a noção de 'competência comum', ou seja, um nível de governo atua prioritariamente sobre um ciclo, ao mesmo tempo em que o outro também poderia fazê-lo. Outro aspecto tange à competência da União de produzir diretrizes e normas nacionais, somada a sua função supletiva e redistributiva, a fim de garantir maior ubiquidade de oportunidades e um padrão mínimo de qualidade de ensino (ABRUCIO, 2010, p. 60). Além disso, o autor ressalta a falta de coordenação do sistema, que resultou numa ausência de regime colaborativo entre os entes federados.

Tais questões se inserem no debate do pacto federativo brasileiro e suscitam problematizações a respeito da repartição não apenas das competências executórias, mas a capacidade tributária de que dispõem os entes da federação para investir e manter seus respectivos sistemas educacionais (CRUZ, 2009). A despeito da descentralização da execução da oferta de educação pública, privilegiando-se as escalas subnacionais, persistem ainda as disparidades nos recursos orçamentários disponíveis para a manutenção das redes educacionais dos entes da federação.

Esse quadro serve de referência sobre as dificuldades que transpassam os entes da federação nos desafios que se impõem ao sistema educacional. Não obstante, o escopo deste trabalho foi trazer reflexões sobre o papel da União, no sistema de educação, a partir da criação dos Institutos Federais de Educação Ciência e Tecnologia. Com isso, o Governo Federal reforçou seu papel como agente responsável pelo fortalecimento da educação nacional, ao criar, em diferentes municípios, novas unidades federais de educação.

Dessa perspectiva, a expansão da rede federal ensino profissional deve ser entendida num contexto de mudanças econômicas e de ação do Estado brasileiro. As unidades educacionais criadas pelo Governo Federal, a partir da ampliação da Rede Federal de Ensino, desde 2005 , assumiram novas perspectivas com a criação dos Institutos Federais, em 2008. Objetiva-se formar profissionais técnicos e de nível superior para a promoção do desenvolvimento local e regional, conjugado ao estímulo da produção de inovações científico-tecnológicas e de resoluções demandadas local e regionalmente. 
Propomos neste trabalho uma reflexão sobre o papel dos Institutos Federais de Educação no desenvolvimento local e regional, incorporando exemplos que sirvam para demonstrar a relevância dessas instituições nessas escalas. 0 artigo foi dividido em duas partes, além da introdução e considerações finais: na primeira, apontamos a emergência do território como estratégia no desenvolvimento local e regional como premissas para os Institutos Federais; na segunda, resgatamos uma discussão a respeito dos conceitos de desenvolvimento local e regional, utilizando-os na interpretação do papel das instituições federais de ensino profissional.

A expansão da rede federal de ensino: emergência do território como estratégia no desenvolvimento socioeconômico local e regional

As desigualdades sociais e regionais que marcam a História do País ensejaram a previsão constitucional de um objetivo a ser alcançado pela República: a erradicação da pobreza e da marginalização, bem como a redução das desigualdades sociais e regionais, conforme previsto no art. $3^{\circ}$ da Constituição Federal de 1988. Os caminhos a serem trilhados no alcance da superação dessas desigualdades são múltiplos. Eles podem englobar ações setorizadas, como é o caso da criação de programas específicos ou de instituições singulares, sendo exemplo emblemático o Departamento Nacional de Obras Contra as Secas (DNOCS), com foco no Nordeste, ou pode envolver ações mais amplas, como a manutenção de uma rede federal de ensino de abrangência nacional.

A par desse panorama, a partir de 2005, o Governo Federal fez a opção política de instituir um planejamento para a expansão sistemática da rede federal de ensino, dividindo-o em três, sendo que a terceira se encontra inconclusa. Coligiram-se critérios que conferissem um sentido lógico ao ordenamento territorial pretendido para a rede, ao não se limitar tão somente a atender ao pleito originado das instituições federais de ensino ou a solicitações políticas. Prezou-se pela escolha de critérios fundamentados, para a provisão de unidades federais de ensino, que contemplasse as diferentes regiões e Unidades da Federação do País, em vista da diminuição da desigualdade de distribuição da rede federal de ensino no território nacional.

Além disso, a adoção de critérios balizadores para a expansão da rede federal de ensino foi calcada em dados sociais, econômicos, populacionais e da base produtiva local de Municípios, Estados e do Distrito Federal. Tais características do programa de expansão denotam a emergência dos elementos constituintes do território como condicionantes imprescindíveis na consecução da política pública de Educação Profissional. 0 ápice do território, e de seus múltiplos aspectos constituintes, como fator sine qua non para a atuação da rede federal de ensino se substancia na criação, em 2008, dos Institutos Federais de Educação, Ciência e Tecnologia.

A Lei $\mathrm{n}^{0} 11.892 / 08$, ao criar os Institutos Federais, expressou, em seu $6^{\circ}$ artigo, a necessidade de orientar a oferta formativa consoante à base territorial das unidades, uma vez que tais instituições, por terem conformação multicampi, devem:

\begin{abstract}
I - ofertar educação profissional e tecnológica, em todos os seus níveis e modalidades, formando e qualificando cidadãos com vistas na atuação profissional nos diversos setores da economia, com ênfase no desenvolvimento socioeconômico local, regional e nacional;

II - desenvolver a educação profissional e tecnológica como processo educativo e investigativo de geração e adaptação de soluções técnicas e tecnológicas às demandas sociais e peculiaridades regionais;

(...)

IV - orientar sua oferta formativa em benefício da consolidação e fortalecimento dos arranjos produtivos, sociais e culturais locais, identificados com base no mapeamento das potencialidades de desenvolvimento socioeconômico e cultural no âmbito de atuação do Instituto Federal; (Grifos nossos)
\end{abstract}

A proeminência do território como fator-chave na atuação dos Institutos Federais foi endossada no discurso do Secretário de Educação Profissional e Tecnológica, Eliezer Pacheco, na época de criação dessa nova institucionalidade.

A estrutura multicampi e a clara definição do território de abrangência das ações dos Institutos Federais afırmam, na missão destas instituições, o compromisso de intervenção em suas respectivas regiões, identificando problemas e criando soluções técnicas e tecnológicas para o desenvolvimento sustentável com inclusão social. Na busca de sintonia com as potencialidades de desenvolvimento regional, os cursos nas novas unidades deverão ser definidos através de audiências públicas e de escuta às representações da sociedade.

(...)

É na compreensão dos aspectos essenciais dessa relação e na sedimentação do sentimento de pertencimento territorial que se torna possível subverter a submissão de identidades locais a uma global. Esse caminho passa necessariamente por uma educação que possibilite ao indivíduo o desenvolvimento de sua capacidade de gerar conhecimentos a partir de uma prática interativa com a realidade. Ao mergulhar em sua própria realidade, esses sujeitos devem extrair e problematizar o conhecido, investigar o não conhecido para poder compreendê-lo e influenciar a trajetória dos destinos de seu lócus. 0 desenvolvimento local, regional ou nacional não pode prescindir do domínio, da produção e da democratização do conhecimento, assim, os Institutos revelam-se, espaços privilegiados de aprendizagem, inovação e transferência de tecnologias capazes de gerar mudança na qualidade de vida de milhares de brasileiros.

0 território de abrangência das ações de um Instituto é em resumo a mesorregião onde se localiza, mas pode ir além dela quando se concebe sua atuação em rede. Em sua intervenção, os Institutos devem explorar as potencialidades de desenvolvimento, a vocação 
produtiva de seu lócus; a geração e transferência de tecnologias e conhecimentos e a inserção, nesse espaço, da mão de obra qualificada. Para tanto, o monitoramento permanente do perfil socioeconômicopolítico-cultural de sua região de abrangência é de suma importância. (PACHECO, 2011, p. 14; 21-22, grifos nossos).

Some-se, a essa perspectiva, aquela delineada pelo Plano Nacional de Educação (2014-2024). Na meta de expansão do ensino técnico prevista no Plano, a primeira das estratégias traçadas estabelece que na oferta dessa modalidade educativa aos Institutos Federais incumbe a responsabilidade na "ordenação territorial".

É nítida a importância conferida ao território na consecução da expansão da rede federal e na abrangência de atuação dos Institutos Federais, ainda que sejam evocadas diferentes terminologias (local, região, regional, mesorregião, ordenação territorial, dentre outras). Sem as clarezas necessárias quanto ao real escopo a ser alcançado pela política pública, tais expressões sintetizam, porém, a intencionalidade que o discurso político, a ação estatal e as mudanças legais imprimem à rede federal de ensino. Assim sendo, alça-se o território à condição de base fundamental na orientação das ações dessas instituições estatais de ensino.

Ao interpretarmos a expansão da rede federal de ensino como estratégia traçada pelo Estado para o desenvolvimento socioeconômico local e regional, entendemos que a estratégia pressupõe "planos da alta administração para alcançar resultados consistentes com a missão e os objetivos gerais da organização" (WRIGHT, KROLL e PARNELL, 2009, p. 24). Ou seja, as ações empreendidas pelo Estado com a expansão da rede federal de ensino visam possibilitar, aos diferentes municípios e regiões, novos instrumentos para a construção do desenvolvimento socioeconômico local e regional, em que o fomento à geração de inovações tecnológicas aparece sobremaneira.

Tais ações estão estritamente correlacionadas aos objetivos gerais do próprio Estado, no sentido de induzir a produção de inovações tecnológicas nas diferentes localidades do País, que resulta claramente da acepção geopolítica de diminuição da dependência brasileira das tecnologias dos países desenvolvidos (IBAÑEZ, 2014, p. 132). Nesse sentido, o território emerge como trunfo para a produção de inovações técnicas e tecnológicas. Recorda-nos Becker (2009, p. 37) que, desde o final do século XX, o território é "desnudado" e reconhecido como "protagonista".

Nessa concepção, a interação social produz o território, que constitui, assim, um ator social. A natureza dos laços sociais em sua interação localizada é a compreensão essencial desse processo; basea- se (sic) na "cooperação", que gera um processo de aprendizagem e produção de conhecimentos tácitos, utilizados para a coordenação do processo, inclusive, pelas empresas. A liderança é considerada crucial nesse processo, na medida em que a vida social dá-se em campos ou arenas, onde o objetivo central da ação é conseguir a cooperação; cooperação que só pode ser obtida com a "habilidade social" dos líderes, entendida essa habilidade como a capacidade de construir coalizões, conseguindo adesões para enfrentar outras coalizões, ou seja, configurando relações de dominação. (BECKER, 2009, p. 37).

Assim, espera-se que os Institutos Federais capitalizem os percursos formativos, as particularidades culturais dos atores sociais e as características econômicas do território de atuação, nas escalas local e regional, para o fomento de produção de inovações científicas e tecnológicas. Essa é, inclusive, uma das premissas basilares dos Institutos, já que se incumbe às instituições orientar sua oferta formativa com base no território de abrangência de atuação e em benefício da consolidação e fortalecimento dos arranjos produtivos ${ }^{1}$, sociais e culturais locais. Portanto, as instituições precisam encaminhar suas atividades acadêmico-científicas com base no mapeamento das potencialidades de desenvolvimento socioeconômico e cultural do município e da região, a fım de prospectá-las em benefício da economia local e regional.

Alguns exemplos de inovações que foram geradas a partir das potencialidades locais podem ser mencionadas. Na Bahia, o Instituto Federal Baiano registrou, em 2016, a patente de um "Equipamento manual para quebra de cacau (Theobroma Cacao)" que, segundo os inventores "refere-se a um equipamento portátil, leve, de baixo custo e acionado manualmente para a 'quebra do cacau, que consta do corte da casca e a separação das sementes da mesma, podendo ser executado por uma única pessoa, de maneira segura, sem contato direto com as sementes e sem prejuízo do rendimento operacional em relação ao processo tradicional, executado por, pelo menos, duas pessoas.". É importante recordar que a Bahia foi responsável por cerca de $70 \%$ da produção cacaueira nacional em $2016^{2}$, o que denota que tal invenção pode trazer benefícios econômicos para a localidade.

No Norte do Brasil, o Instituto Federal do Amazonas patenteou uma invenção sobre o processo de prepara-

\footnotetext{
1"(...) o conceito de arranjos produtivos locais - APLs - é utilizado para referenciar aquelas aglomerações produtivas que não apresentam significativa articulação entre os agentes locais e que, portanto, não podem se caracterizar como sistemas (produtivos locais)" (VARGAS, 2002, p. 10)

${ }^{2}$ Segundo informações disponíveis na página do Ministério da Agricultura, disponível em: < http://www.mda.gov.br/sitemda/noticias/ cacau-da-bahia-70-da-produ\%C3\%A7\%C3\%A3o-nacional>. Acesso em 23 abril 2019.
} 
ção e conservação do tucupi ${ }^{3}$ para o consumo humano. Na visão dos inventores, essa invenção se refere

ao processo de preparação e conservação do tucupi para o consumo humano. Este invento compreende o processo de preparo do tucupi temperado, o processo de congelamento em diferentes frações de volumes do tucupi, tendo como produtos finais o Tucupi Temperado In Natura e o Tucupi Temperado Congelado. São vislumbradas vantagens técnicas e econômicas ao produto, que representa um ingrediente importante nos hábitos alimentares peculiares da região amazônica, por proporcionar aumento do tempo de prateleira, qualidade, sanidade e promoção da expansão comercial do tucupi por meio da aplicação da técnica de congelamento rápido, após redução do teor de cianeto. 0 invento proporcionará maior aproveitamento da mandioca e enriquecimento de sua cadeia produtiva. ${ }^{4}$

$\mathrm{Na}$ busca de melhorias das cadeias produtivas, no aprimoramento de produtos ou processos produtivos, dentre outros, as invenções patenteadas pelos Institutos nos servem de exemplos de como pode transcorrer a prospecção de características locais e regionais. Nesse sentido, tais invenções refletem um modo pelo quais essas instituições buscam atender às localidades onde se encontram, podendo ter tais inventos impactos efetivos na economia. Apesar de não ter sido o escopo deste trabalho tratar sobre as formas pelas quais essas invenções têm sido apropriadas, é importante registrar a relevância de se problematizar quais são os atores e agentes sociais que efetivamente se apropriam e se beneficiam dessas inovações.

\section{Política Pública com foco no desenvolvimento local e regional}

A política pública de Educação que os Institutos Federais representam revela a importância das instituições de ensino no desenvolvimento local e regional, ressaltando-se a atuação do Estado não apenas como supridor para demandas da economia local e regional mas também como indutor e fomentador de novas atividades econômicas nessas escalas. Pode-se citar o exemplo da unidade do Instituto Federal do Rio de Janeiro (IFRJ) localizada no município Engenheiro Paulo de Frontin, no estado do Rio de Janeiro, que tem buscado meios de induzir a formação de um adensamento produtivo local voltado para a área de informática e de jogos digitais naquela localidade (SOUZA, 2016).

No contexto contemporâneo, a escala de atu-

${ }^{3}$ Espécie de molho feito com água de goma e pimenta, que acompanha vários pratos da cozinha do Norte do Brasil.

${ }^{4}$ Informações extraídos da página do Instituto Nacional da Propriedade Industrial (INPI), em 23 de abril de 2019. ação do Estado deixa de ser prioritariamente a macrorregional, reconfigurando-se, ao se privilegiar as escalas subnacionais, uma vez que a

(...) noção de reescalonamento do Estado caracteriza, assim, a forma transformada do Estado no capitalismo contemporâneo. Se no século 20 as estratégias políticas tinham como foco estabelecer uma hierarquia centralizada do poder, hoje, elas estão superadas, na medida em que uma configuração do estatismo mais policêntrica, multiescalar e não-isomórfica está sendo criada. (BRENNER, 2004, apud BECKER, 2009, p. 42).

Becker (2009) nos lembra de que, com a erosão do keynesianismo espacial, não se gerou um processo de descentralização de escalas, em que só uma escala substituiria as demais. Tratar-se-ia, em realidade, de um reescalonamento das funções do poder do Estado, que passa por um processo de transformação qualitativa.

\begin{abstract}
Em contraste com as previsões de desnacionalização, das capacidades regulatórias do Estado, seja pelo crescimento dos blocos supranacionais seja por regionalização, o que ocorre é a permanência das instituicões nacionais espacialmente reconfiguradas, como as mais importantes animadoras e mediadoras da reestruturação político-econômica em 'todas as escalas geográficas'. (BECKER, 2009, p. 42-43).
\end{abstract}

Nessa conjuntura, as novas tendências do planejamento estatal evidenciam essa reconfiguração, como é exemplo o "Estudo da Dimensão Territorial do PPA e do Planejamento Governamental a Longo Prazo", elaborado pelo Centro de Gestão e Estudos Estratégicos (CGEE), de 2007. Além de o território ter, incontestavelmente, emergido como um norte que orienta as ações do Estado, as diferentes escalas subnacionais surgem, ao mesmo tempo, como locus privilegiado da ação estatal.

O território é um guia para orientar a ação...; a política territorial não consiste mais em distribuir recursos e riquezas já criadas, mas ao contrário, em despertar os potenciais para a criação de riquezas e coordenações novas...; O grande desafio do planejamento é promover, de forma coordenada, o deslanchar das muitas oportunidades de investimento que emergem das realidades regionais e locais...; Garantir a coesão territorial é corolário desse desafio...; Insuficiência das políticas regionais clássicas voltadas para macrorregiões inteiras. Políticas necessitam ser operacionalizadas segundo as diferentes escalas territoriais (GALVÃO, 2007, apud BECKER, 2009, p. 47, grifos nossos)

As ações promovidas pelo poder público, nessas escalas, referem-se, antes de tudo, a uma estratégia que busca fortalecer eengajar a competição em diferentes territórios.

Sob os esforços da ciência e os discursos e ações do planejamento, não há tanto de novo na essência: tratase de como competir mais e melhor. Destacam-se, na verdade, processos de aprofundamento da competição. 
É o caso de engajar os territórios na competição em diferentes escalas, envolvendo o seu tecido social e o conhecimento produzido, e promovendo a cooperação e o aprendizado para competir. (BECKER, 2009, p. 47)

No Brasil, de acordo com Rückert (2005), as políticas de desenvolvimento endógeno na escala local-regional se impulsionaram principalmente a partir das transformações político-institucionais. Tais mudanças decorreram da descentralização político-administrativa, ao se fortalecer as escalas subnacionais, com a redistribuição de competências políticas e fiscais. Possibilitou-se, desse jeito, o estímulo às denominadas "vocações regionais e locais", em que o desenvolvimento passa a ser assumido pelos locais e regiões distantes do poder central, através de novos atores locais e regionais que surgem nesse cenário.

Não obstante, deve-se advertir que os vocábulos "vocação local/regional" e "potencialidade local/ regional" carregam diferentes acepções. Silva (2005), ao tratar das distinções entre essas terminologias, recorda que as potencialidades se referem a algo que tem a "qualidade de potencial". A potência indica que algo ainda é "virtual, não-concreto e possível", e que se pode estimular através de ações diversas.

\footnotetext{
(...) a potencialidade de dada atividade (associada às suas tendências conjunturais, micro e macro) em determinado lugar estará diretamente ligada às potencialidades de dado território se houver efetivamente, a aplicação de força real (política, por exemplo), para que 'o seu planejamento torne concreta e atingível a potencialidade espacial' (SILVA, 2005, p. 160).
}

Já "vocação local/regional" informa um sentido de "predestinação, escolha, aptidão ou talento" para erroneamente designar "fatos territoriais" (SILVA, 2005, p. 162). Deve-se rechaçar esse vocábulo, uma vez que ele busca conferir uma "naturalização das atividades aos territórios", pois "dá ao espaço escolhas e decisões próprias, ou seja, uma situação inata de ação que nega, minimamente, a divisão do trabalho nos territórios" (ibid.).

A partir de meados da década de 80 , a questão de se a comunidade territorial local conteria potencialidades para o poder, abriu espaço para a multiplicidade de organizações interessadas no fortalecimento da comunidade local e na política de descentralização de decisão (WILSON, 1995, apud RÜCKERT, 2005, p. 87). A escala local, tida como nova unidade de análise, é percebida pautada numa nova lógica de articulação dos espaços, ao se privilegiar o aproveitamento dos recursos endógenos para diversificar o crescimento, gerar emprego e em no- vas formas de gestão pelos agentes locais. Contrapõe-se, assim, ao desenvolvimento centralizado que teve grande peso no período anterior à Constituição de 1988.

É a partir desse contexto que são concebidas as políticas públicas que vislumbram fortalecer o desenvolvimento local e regional. Os Institutos Federais surgem calcados nessa premissa, ao se apresentarem como instituições que visam contribuir para o desenvolvimento socioeconômico nessas escalas. Reforça-se, com isso, a importância das escalas subnacionais, uma vez que

em uma escala macro regional aumentam as tensões geográficas e se aguça a competição inter-regional e interurbana - com a emergência do que Santos (1996) caracterizou de "guerra dos lugares" e de uma nova organização do espaço enovas configurações regionais, em que antigos protagonistas passaram a ocupar um segundo plano. 0 que fez com que especialistas em planejamento, consultores e governantes, em diversas escalas de poder, buscassem e tomassem iniciativas "no intento de mobilizar os principais atores locais em torno de uma visão partilhada do futuro" (Pichierri, 2002:695) com vistas a recuperar a preeminência perdida. (LIMONAD, 2005, p. 7855)

A preocupação com o desenvolvimento local e regional se elevou diante dos fracassos das políticas com caráter macroestruturais, a partir da percepção de que ainda persistem as graves disparidades sócioespaciais intra e inter-regionais, tanto quanto entre os municípios do País.

É muito evidente que o tema do desenvolvimento local vem sendo colocado na agenda da discussão políticoeconômico-social e cultural devido ao fracasso das abordagens macroestruturais em romper, no plano social com a desigualdade, no plano econômico com a concentração do poder, no plano político com a declarada insuficiência dos mecanismos e processos da democracia representativa e no plano cultural com a folclorização trabalhada pela 'indústria-cultural' como exotismo (...) (BAVA, 2002, apud ULTRAMARI \& DUARTE, 2012, p. 24)

0 conceito de desenvolvimento local abrange diferentes perspectivas, ao não se limitar às formas de como valorizar o local e a comunidade e às diversas possibilidades de iniciativas que buscam soluções para problemas enfrentados no cotidiano.

O Desenvolvimento Local é tema controverso sobre o qual não há consenso entre os especialistas, nem no Brasil nem no debate internacional. A controvérsia não é apenas conceitual, e também existe no plano metodológico. Há quem diga que as experiências de desenvolvimento local são apenas a expressão espacial de um novo arranjo industrial 'pós-fordista'. Para outros, as experiências de desenvolvimento local têm dinâmicas próprias e são mais que reflexo da reorganização internacional do capital. Para outros, ainda, o local seria um espaço privilegiado para experimentações contra-hegemônicas. (FRANÇA et al., 2004, p. 5) 
As diferentes localidades e regiões dispõem de características variadas, sejam elas econômicas, físicas, sociais, culturais, entre outras, que são importantes na capacidade de produzir conhecimento, de aprender e inovar (ALBAGLI \& MACIEL, 2004, p. 11). Nas inter-relações que se constroem nas escalas local, os diferentes atores envolvidos são fundamentais no uso do conhecimento de que dispõem para liderar processos de crescimento e mudança, ou seja, de desenvolvimento local (VÁZQUEZ-BÁRQUERO, 1999).

Nessas interações locais, desenvolve-se um conhecimento coletivo, o qual é diferenciado e desigualmente distribuído, podendo ou não constituir importante fonte de dinamismo para aquele ambiente. Esse conhecimento coletivo não corresponde simplesmente à soma de conhecimentos de indivíduos e organizações; resulta das sinergias geradas a partir dos vários tipos de interação; e altera-se inclusive na sua interseção com a circulação globalizada de informação e conhecimento. (ALBAGLI \& MACIEL, 2004, p. 11).

A promoção do desenvolvimento local pretende responder "às exigências de transformação produtiva, empresarial e organizacional que, nesta fase 'pós-fordista', obrigam a buscar formas mais flexíveis e eficientes no âmbito da acumulação do capital" (DIAS \& MATOS, 2012, p. 34). As transformações não ocorrem somente no âmbito econômico, mas resvalam, também, no âmbito político. Dessa maneira, são "necessárias adaptações socioinstitucionais e reformas políticas, que implicam a modernização do Estado, assim como o estímulo da participação cidadã e o fomento das atitudes inovadoras e criativas na sociedade local"5 (ALBUQUERQUE, 2004, p. 48).

Para Albuquerque (2004), um dos aspectos fundamentais do desenvolvimento econômico local são as instituições educacionais.

Otra capacidad fundamental (para o desenvolvimento econômico local) se refiere a la movilización y orientación de las instituciones territoriales educativas y de capacitación, de modo que contemplen de forma prioritaria las necesidades y problemas del perfil productivo local. Inútil es subrayar la importancia de la educación y la capacitación como elemento determinante para reforzar las capacidades de desarrollo, mejorar la competencia de los recursos humanos y estimular aptitudes creativas e innovativas. Sin embargo, este papel es a menudo subestimado a la hora de emprender actuaciones ante el actual cambio estructural, el cual no puede ser atendido eficazmente mediante una simple educación de tipo generalista, que no es suficiente para capacitar a las personas ante

${ }^{5}$ Leia-se, no original: "necesarias adaptaciones socioinstitucionales y reformas políticas, que implican la modernización del Estado, así como el estímulo de la participación ciudadana y el fomento de las actitudes innovadoras y creativas en la sociedad local". (ALBUQUERQUE, 2004, p. 48). los retos que tienen que enfrentar en la actual fase de transición tecnológica organizativa ${ }^{6}$ (ALBUQUERQUE, 2004, p. 65-66).

Além disso, a dimensão sociocultural, política e administrativa conformam novas perspectivas para 0 desenvolvimento local, em que o território constitui espinhal dorsal de fomento à competitividade. Tendo em vista que as localidades e regiões competem nacional e globalmente, reforçam-se as estratégias que visam ampliar a competitividade local e regional. Concomitantemente, buscam-se atrair novos investimentos e consumidores com o objetivo de beneficiar as suas localidades e regiões (DINIZ, 2001).

En resumen, puede decirse que el desarrollo económico local es un proceso de crecimiento y cambio estructural de la economía de una ciudad, comarca o región, en que se pueden identificar al menos tres dimensiones: una económica, caracterizada por un sistema de producción que permite a los empresarios locales usar eficientemente los factores productivos, generar economías de escala y aumentar la productividad a niveles que permiten mejorar la competitividad en los mercados; otra sociocultural, en la cual el sistema de relaciones económicas y sociales, las instituciones locales y los valores sirven de base al proceso de desarrollo, y otra política y administrativa, en la que las iniciativas locales crean un entorno local favorable a la producción e impulsan el desarrollo. ${ }^{7}$ (VÁZQUEZBÁRQUERO, 2001, p. 22).

A Organização Internacional do Trabalho (OIT) (2006), ao conceituar o desenvolvimento local, entende que se trata de

(...) a participatory process that encourages partnership

${ }^{6 "}$ "Outra capacidade fundamental (para o desenvolvimento econômico local) se refere à mobilização e orientação das instituições territoriais educativas e de capacitação, de modo que contemplem de forma prioritária as necessidades e problemas do perfil produtivo local. Inútil é destacar a importância da educação e da capacitação como elemento determinante para reforçar as capacidades de desenvolvimento, melhorar a competência dos recursos humanos e estimular atitudes criativas e inovativas. Entretanto, este papel é frequentemente subestimado na hora de empreender atuações diante da atual mudança estrutural, o que não pode ser atendido eficazmente mediante uma simples educação do tipo generalista, que não é suficiente para capacitar a pessoas diante dos desafios que têm que enfrentar na atual fase de transição tecnológica e organizativa." (tradução nossa).

${ }^{74} \mathrm{Em}$ resumo, pode-se dizer que o desenvolvimento econômico local é um processo de crescimento e mudança estrutural da economia de uma cidade, comarca ou região, no qual se podem identificar ao menos, três dimensões: uma econômica, caracterizada por um sistema de produção que permite aos empresários locais usar eficientemente os fatores produtivos, gerar economias de escala e aumentar a produtividade a níveis que permitem melhorar a competitividade nos mercados; outra sociocultural na qual o sistema de relações econômicas e sociais, as instituições locais e os valores servem de base ao processo de desenvolvimento; e outra, política e administrativa, em que as iniciativas locais criam um entorno local favorável à produção e impulsionam o desenvolvimento." (tradução nossa). 
arrangements between the main private and public stakeholders in a defined territory. This process enable these stakeholders to design and implement jointly a common development strategy that makes use of local resources and competitive advantage of the territory in a global context with the final objective of creating decent jobs and stimulating economic activity. (OIT, 2006$, p. 47$)^{8}$

As diferentes abordagens sobre o conceito de desenvolvimento local refletem que o desenvolvimento local é multifacetado e difuso. Pretende-se abarcar, na escala local, a superação das dificuldades e dos desafios existentes, através de um processo em que os diversos agentes sociais e econômicos locais, sejam eles do setor público, privado ou do terceiro setor, atuem com proveito mais eficiente e sustentável dos recursos de que dispõem. Ademais, reforça-se a necessidade de se estabelecer mecanismos que incentivem o empreendedorismo local e a criação de um ambiente inovador no território (DIAS \& MATOS, 2012, p. $35)$, com vista a robustecer o desenvolvimento local.

Nos enfoques sobre o desenvolvimento, em que o planejamento é estabelecido pelo governo central, a escala local integra uma estratégia de desenvolvimento na qual os recursos naturais, socioculturais, econômicos e administrativos estão subordinados a uma lógica de desenvolvimento que busca atender aos setores mais dinâmicos do ambiente econômico (DIAS \& MATOS, 2012, p. 36). Nesse sentido, parte-se da premissa de que são esses setores os carros-chefes da economia e, portanto, o desenvolvimento passaria necessariamente pelo seu crescimento. Por conseguinte, as escalas locais se vinculariam a estratégias que desarticulam e rompem as estruturas socioculturais locais, que se veriam obrigadas, para sobreviverem, a tornarem-se caudatárias de um processo externo, embora nacional (ibid.).

Em sentido diverso, a perspectiva de desenvolvimento socioeconômico local implica uma maior participação dos atores locais, tanto no que se refere às elaborações de estratégias, quanto à coordenação do processo de crescimento local que envolve o conjunto de instituições instaladas no território. Assim, compreendemos que a estratégia do Governo Federal em ampliar a rede federal de ensino, para o aproveitamento das potencialidades locais e atendimento às especializações econômicas existentes, busca fortalecer a eco-

8"(...) um processo participativo que encoraja acordos de colaboração entre os mais importantes atores públicos e privados de um determinado território. Esse processo possibilita esses atores a elaborar e implementar conjuntamente uma estratégica de desenvolvimento que faz o uso dos recursos locais vantagens competitivas do território no contexto global com o objetivo final de criar empregos decentes e estimular a atividade econômica." (tradução nossa). nomia local e o desenvolvimento territorial. Com isso, os Institutos Federais se revelam atores estratégicos quando formam profissionais capacitados para atender às demandas locais, na promoção do desenvolvimento de inovações técnicas e tecnológicas que aproveitam as potencialidades locais e regionais, e em ações que propiciem sinergias entre os atores locais e regionais.

Pode-se exemplificar a importância da relação entre as unidades locais dos Institutos Federais e a escala lo$\mathrm{cal} /$ regional no desenvolvimento. No município de Engenheiro Paulo de Frontin, no estado do Rio de Janeiro, o campus do IFRJ instalado na localidade, em parceria com a Prefeitura, elaborou um projeto que foi contemplado em Edital nacional promovido pelo Ministério das Comunicações para as "Cidades Digitais", em 2012. Tratava-se de um programa que visou a construção de redes de fibras ópticas que possibilitassem a conexão entre os órgãos públicos, bem como o acesso da população a serviços de governo eletrônico e a espaços de uso de Internet.

Assim, o município foi dotado de uma rede de infraestrutura técnica que ampliou o acesso à Internet para a população local, provendo a localidade de melhores condições de infraestrutura. Ao considerarmos que o município possuía uma das mais baixas Densidades Domiciliares de Acesso à Banda Larga Fixa $(\mathrm{DBL})^{9}$ no estado do Rio de Janeiro (86ª colocação dos 92 municípios fluminenses) em 2011, a ampliação da oferta desse serviço contribuiu com o desenvolvimento local, pois em 2015 essa densidade se elevou e o município figurava na $49^{a}$ colocação dos 92 municípios fluminenses.

Além disso, os Institutos Federais, a princípio, credenciar-se-iam como instituições dotadas de recursos humanos e materiais adequados que dispõem de seus quadros institucionais - docentes, laboratórios, pesquisa aplicada etc. - em proveito para o desenvolvimento local e regional, ainda que, como usualmente acomete o serviço público de modo geral, haja limitações orçamentárias que afetem a realização dessas atividades. Se, por um lado, a política pública de expansão da rede federal de ensino foi concebida no âmbito do governo central e os recursos daí se originam, por outro, o foco mormente se dirige às escalas subnacionais. Visa-se, no seu âmago, corresponder às expectativas dos atores locais, que deveriam poder influenciar as decisões das

${ }^{9}$ Os cálculos de densidade são obtidos a partir da divisão dos acessos de banda larga fixa pela população total do município. Os dados de população são obtidos na Estimativa da População - IBGE de 2011 e 2015 e os de acesso à internet fixa com base Conjunto de indicadores compilado pelo MCTIC sobre temas da área de Comunicações, como internet, telefonia, radiodifusão e serviços postais disponíveis na página do Ministério: < https://www.mctic.gov.br/mctic/opencms/indicadores/detalhe/dados_setor_comunicacoes/Dados-do-Setor-de-Comunicacoes.html>. Acesso em 22 abril 2019. 
próprias instituições que importem às realidades locais.

De outra perspectiva, Diniz (2001) aponta que a ampliação da mobilidade do capital e da fluidez do mercado, que buscam as localizações ou nichos de maior lucratividade, reforça a competição entre as localidades. Entende o autor que o sucesso econômico de cada região, localidade ou País dependerá da habilidade de construir ou reforçar uma especialização que logre constituir vantagens comparativas efetivas e dinâmicas, balizada no estoque de atributos e da capacidade de promoção da inovação. Além desses elementos, o sucesso advém da capacidade do empresariado em promover pesquisa e desenvolvimento, na elaboração de novos produtos ou processos, que se configurem como um sucesso econômico da empresa.

Ao mesmo tempo, conflui para o sucesso a capacidade local de aprender, no sentido de se estabelecer uma atmosfera de transformação e progresso. Isso indica que a capacidade de atração de cada região ou localidade passa a depender, cada vez mais, da combinação dos elementos locais, que envolve os aspectos econômicos, sociais, culturais, naturais e políticos. Essas características se inter-relacionam através de um processo cultural, construído e reconstruído no decorrer do processo de interação entre os agentes e atores locais e regionais, as instituições locais, o poder público local, entre outros.

$\mathrm{Na}$ perspectiva do desenvolvimento regional, Amaral Filho (2001, p. 262) entende que um processo de crescimento econômico se referencia a uma "contínua ampliação da capacidade de agregação de valor sobre a produção". Ademais, refere-se à "capacidade de absorção da região, cujo desdobramento é a retenção do excedente econômico gerado na economia local e/ou a atração de excedentes provenientes de outras regiões". Resultar-se-ia, a partir dessa perspectiva de desenvolvimento regional, a ampliação do emprego, do produto e da renda do local e/ou da região.

A região aparece como uma unidade fundamental da vida social e de manifestação de convenções e regras que coordenam a ação dos agentes econômicos e estabelecem interdependências não mercantis (PIRES DO RIO, 2012, p. 169). A escala regional se apresenta como campo de negociações para a retomada do desenvolvimento e das mudanças nas formas de gestão do território e pode refletir as características de inércia e durabilidade das instituições (ibid., p. 169). Entretanto, como nos alerta Limonad (2005):

A questão do desenvolvimento local-regional hoje, portanto, gira em torno da possibilidade de construção de novos pactos, acordos territoriais. E isto exige, ao contrário do que pensam os defensores do planejamento estratégico, não a construção de um cenário futuro plausível com os principais protagonistas. Nem em se concentrar apenas no local. Primeiro, porque a solução não se encontra na construção de uma imagem plausível e sedutora, como pensam os primeiros; e segundo, porque os atores locais, hegemônicos ou não, não estão limitados ao local e à escala local, mas ao contrário encontram-se articulados em múltiplas escalas. Enfim, terceiro, porque hoje as perspectivas de preservação, apropriação, aproveitamento dos recursos naturais conquistaram um caráter geopolítico que extrapola as escalas nacionais de interesse (...)

Parece-nos um equívoco manter a postura de pensar localmente para agir globalmente, uma vez que para que haja um desenvolvimento local, e mesmo regional, os diferentes atores locais devem estar articulados em múltiplas escalas. Não se trata mais de produzir localmente para resolver demandas localizadas regionalmente, mas de produzir localmente para abastecer o mercado mundial, embora mesmo esta produção "local" esteja agora articulada em rede em múltiplas escalas geográficas. Neste sentido para produzir localmente e promover o desenvolvimento local é necessário pensar e articular-se além do local. (LIMONAD, 2005, p. 7862-7863).

Destarte, deve-se considerar que as políticas e práticas específicas para o desenvolvimento local não podem deixar de contemplar as demais escalas, em particular a escala regional. Isso porque tais políticas e práticas não são construídas pragmaticamente de uma hora para outra, mas se desenvolvem historicamente no território em contextos e condições próprias, juntamente com a articulação e a organização em diferentes escalas. Ademais, a acumulação de capital e as lutas de classe ocorrem em campos geográficos de limites e possibilidades variáveis: as formas do Estado, os imaginários sociais, o desenvolvimento geograficamente desigual e identidades e interesses historicamente arraigados, entre outras coisas necessitam ser considerados (COX, 2004).

O conceito de desenvolvimento não é unívoco, ao contrário, concorrem visões diferentes em sua acepção. Historicamente a concepção de desenvolvimento esteve ligada a uma perspectiva de cunho econômico, porém, tem-se ampliado a abrangência de sentido, a partir das insuficiências e limitações percebidas numa visão meramente economicista do desenvolvimento. No âmbito da economia, foram acirradas as disputas sobre a definição do desenvolvimento, uma vez que os economistas foram impelidos a elaborarem um modelo de desenvolvimento que envolvesse não apenas as variáveis econômicas mas também as sociais.

Souza (1993, p. 5) informa que havia duas correntes no pensamento econômico: a primeira entendia o crescimento econômico como sinônimo de desenvolvimento, enquanto a segunda pressupunha ser o crescimento econômico condição imprescindível, mas insuficiente, para o desenvolvimento. Para a segunda corrente de eco- 
nomistas, o crescimento era a simples variação quantitativa do produto, mas o desenvolvimento se caracterizaria por mudanças qualitativas no modo de vida das pessoas, nas instituições e nas estruturas produtivas.

Para North (1990), "não são capacidades inovadoras, democratização do ensino, acumulação que causam o desenvolvimento - esses processos "são" o desenvolvimento", uma vez que "o desenvolvimento reside nas instituições, nas formas de coordenar ações individuais e grupos" (NORTH, 1990, apud BECKER, 2012, p. 4). Não obstante, North (1990) alerta para os fatores que causam a inércia nas mudanças institucionais: a trajetória dependente (path dependence) de condições históricas originais e a acomodação após ter alcançado uma solução.

Para Souza (2013, p. 275), no âmbito da Geografia, o termo desenvolvimento quer dizer, a princípio, a busca, um processo de pôr-se em movimento, quase por definição, aberto e imprevisível. Para o autor, a ideia de desenvolvimento esteve ligada, no discurso capitalista do "desenvolvimento econômico", a uma noção em que o desenvolvimento se daria por "etapas" que seriam conhecidas de antemão. Souza (2013) sugere, de início, que se entenda o desenvolvimento como uma "transformação social para melhor, propiciadora de meIhor qualidade de vida e maior justiça social ${ }^{10 "}$. Em vista dessa razão, o desenvolvimento, e aí entendido como desenvolvimento sócioespacial, configurar-se-ia como um "direito e uma tarefa dos próprios agentes sociais".

Aos diferentes enfoques do desenvolvimento, acresce-se o conceito de desenvolvimento humano que é mais

(...) amplo do que o de desenvolvimento econômico, estritamente associado à idéia de crescimento. Isso não significa contrapô-los. Na verdade, a longo prazo, nenhum país pode manter - e muito menos aumentar - o bem-estar de sua população se não experimentar um processo de crescimento que implique aumento da produção e da produtividade do sistema econômico, amplie as opções oferecidas a seus habitantes e lhes assegure a oportunidade de empregos produtivos e adequadamente remunerados. Por muito tempo foi esquecido que as pessoas são tanto os meios quanto o fim do desenvolvimento econômico. Por conseguinte, o crescimento econômico é condição necessária para o desenvolvimento humano (e social) e a produtividade é componente essencial desse processo. Contudo, o crescimento não é, em si, o objetivo último do processo de desenvolvimento; tampouco assegura, por si só, a melhoria do nível de vida da população. (PNUD, 1996, p.01).

Rodrigues (1993, p. 20) assevera que "o crescimento econômico carece de sentido, se não consegue promover, em última instância, o desenvolvimento humano (e social), entendido como a

${ }^{10}$ Conferir a discussão realizada por Barzotto (2003) sobre a gênese, estrutura e aplicação do conceito de justiça social. realização (ou satisfação) pessoal dos indivíduos de um país/região". Acrescentaríamos, além disso, que o

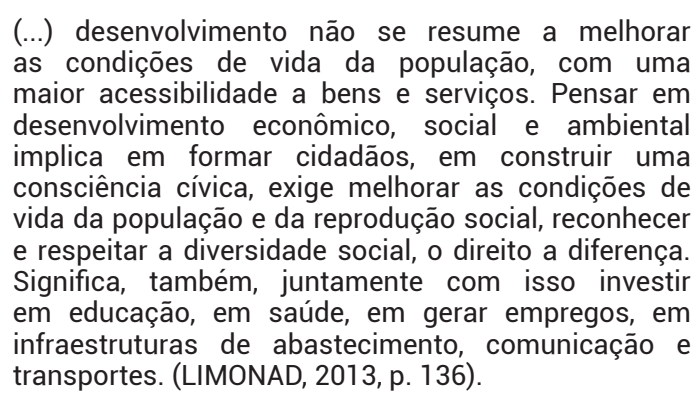

Numa reflexão renovada sobre o tema, Amartya Sen (2010) defende a perspectiva de que o desenvolvimento deve ser entendido como 'liberdade'. 0 autor sustenta que $o$ aumento das liberdades substantivas de que as pessoas desfrutam é o principal fim do desenvolvimento, posto que são essas liberdades "componentes constitutivos" do desenvolvimento (SEN, 2010, p. 19). 0 autor sustenta que essas liberdades e direitos também contribuem muito eficazmente para o progresso econômico e, em vista disso, não se deve estabelecer a posteriori a relevância de tais liberdades para o desenvolvimento.

$\mathrm{Na}$ visão do autor, a liberdade se relaciona à expansão de "capacidades" (capabilities) que as pessoas dispõem para levar o tipo de vida que elas valorizam (SEN, 2010, p. 33). Além disso, essas capacidades podem ser aumentadas pelas políticas públicas, tal como "a direção da política pública pode ser influenciada pelo uso efetivo das capacidades participativas do povo" (ibid.). Sen (2010) sustenta que a relevância da liberdade individual para o desenvolvimento se relaciona com a "avaliação" e "eficácia".

Nessa perspectiva, o êxito da sociedade deve ser avaliado conforme as liberdades substantivas de que os membros da sociedade desfrutam. Destaca o autor que, além de ser importante por si mesmo para a liberdade global da pessoa, a liberdade favorece a oportunidade de a pessoa ter resultados valiosos. 0 aumento da liberdade individual melhora o potencial das pessoas para cuidarem de si mesmas e para influenciarem o mundo, bem como são determinantes na iniciativa individual e na eficácia social, questões imprescindíveis no processo de desenvolvimento.

A expansão da liberdade é o fim primordial e o principal meio de desenvolvimento. Distingue Sen (2010) que o fim primordial da liberdade pode ser entendido pelo seu "papel constitutivo". Como meio de desenvolvimento, a liberdade assume um "papel instrumental". O papel constitutivo se refere à importância da liberdade substantiva no enriquecimento da vida. 
A liberdade substantiva inclui as capacidades elementares, tais como, "condições de evitar privações como a fome, a subnutrição, a morbidez evitável e a morte prematura", tal como "as liberdades associadas a saber ler e fazer cálculos aritméticos, ter participação política e liberdade de expressão" etc. (SEN, 2010 , p. 55). 0 papel instrumental da liberdade humana

(...) concerne ao modo como diferentes tipos de direitos, oportunidade e intitulamentos (entitlements 11) contribuem para a expansão da liberdade humana em geral e, assim, para a promoção do desenvolvimento. (...) A eficácia da liberdade como instrumento reside no fato de que diferentes tipos de liberdade apresentam inter-relação entre si, e um tipo de liberdade pode contribuir imensamente para promover liberdades de outros tipos. Portanto, os dois papéis estão ligados por relações empíricas, que associam um tipo de liberdade a outros. (SEN, 2010, p. 56-57).

Sen (2010, p. 58) divide a liberdade instrumental em cinco tipos, ainda que não esgote os tipos existentes: liberdades políticas, facilidades econômicas, oportunidades sociais, garantias de transparência e segurança protetora. As oportunidades sociais são o tipo de liberdade instrumental que mais se referem à importância da educação para o desenvolvimento. Entende o autor que as oportunidades são as disposições que a sociedade estabelece nas áreas de educação, saúde etc., que influem na liberdade do indivíduo viver melhor.

A educação, por exemplo, possibilita ao cidadão não apenas conduzir a própria vida, mas permite uma participação mais efetiva em atividades econômicas e políticas. 0 autor cita o analfabetismo como uma barreira à participação em atividades econômicas que requeiram produção segundo especificações ou que exijam um rigoroso controle de qualidade. Igualmente, a incapacidade de ler ou de se comunicar por escrito inviabiliza a participação política do indivíduo.

A ampliação da rede federal de ensino aumenta o acesso à educação pública profissional e de nível superior, o que constitui o fortalecimento do desenvolvimento local e regional, em especial em localidades que não dispunham de instituições dotadas de recursos financeiros e humanos de alta capacidade. Exemplifica-se com a construção do Parque Acadêmico Industrial

\footnotetext{
11"O entitlement de uma pessoa é representado pelo conjunto de pacotes alternativos de bens que podem ser adquiridos mediante o uso dos vários canais legais de aquisição facultados a essa pessoa. Em uma economia de mercado com propriedade privada, o conjunto do entitlment de uma pessoa é determinado pelo pacote original de bens que ela possui (denominado 'dotação') e pelos vários pacotes alternativos que ela pode adquirir, começando com cada dotação inicial, por meio de comércio e produção (denominado seu 'entitlement' de troca"). Uma pessoa passa fome quando seu entitlment não inclui, no conjunto (que é formado pelos pacotes alternativos de bens que ela pode adquirir), nenhum pacote de bens que contenha uma quantidade adequada de alimento." (SEN \& DRÈZE, Hunger and public action, 1989).
}

na unidade do Instituto Federal Fluminense no município de Itaperuna, localizado no noroeste do estado do Rio de Janeiro, compondo um complexo de laboratórios em vista da realização de práticas para o desenvolvimento de inovação, além de servir para a formação acadêmico-profissional dos discentes do Instituto.

Além disso, no município de Presidente Figueiredo, no estado do Amazonas, das três escolas locais que participaram do Exame Nacional do Ensino Médio - ENEM 2015, sendo uma da rede privada, outra da rede estadual e outra um instituto federal, a maior média geral no Exame foi do instituto federal $(549,26)$, seguido pela rede privada $(542,80)$ e estadual $(466,88)$. Ao se correlacionar os dados de formação docente, naquele ano, somente no Instituto Federal havia docentes com Mestrado e/ou Doutorado ${ }^{12}$.

Em Alagoas, no município de Penedo, o instituto federal local, a despeito de seu corpo discente ser de nível socioeconômico médio baixo, diferentemente das cinco escolas privadas locais que congregavam alunos de estratos sociais maiores (médio, médio alto e alto), o resultado no ENEM do mesmo ano foi superior no instituto federal $(568,94)$ do que nas demais escolas privadas (médias entre 498,64 e 566,78).

Entendemos, então, que os exemplos supramencionados são indicativos importantes para se interpretar a relevância dessas instituições no desenvolvimento nas escalas subnacionais. Outros múltiplos exemplos e práticas que ocorrem no cotidiano das atividades empreendidas por essas instituições de ensino reforçam a necessidade de se investigar os impactos que trazem às diferentes localidades e regiões do País.

\section{Considerações Finais}

A política pública estabelecida pelo Governo Federal, consubstanciada na criação dos Institutos Federais, incorpora a perspectiva territorial como base imprescindível para aumentar as potencialidades de desenvolvimento nas escalas subnacionais. Incrementa-se, com isso, a densidade organizacional dos territórios (RÜCKERT, 2005, p. 87), cujos efeitos podem ser interpretados na elevação da educação da população, o alargamento das possibilidades de se gerar inovações técnicas e tecnológicas, o estabelecimento de redes colaborativas que articulem os atores e agentes sociais locais e regionais, a atuação em rede que mobiliza municípios circunvizinhos etc.

12Informações extraídas do Censo da Educação Básica 2015 e ENEM 2015, disponíveis na página do Instituto Nacional de Estudos e Pesquisas Educacionais Anísio Teixeira (INEP). 
Os Institutos Federais se constituem, portanto, como mais um vetor do fortalecimento necessário para o desenvolvimento de "regiões inteligentes" (FERRÃO, 2002). Em vista disso, deve-se estimular um ambiente propício à troca compartilhada de informações e a criação de sinergias entre os atores e agentes sociais locais, as empresas, o terceiro setor e as instituições para o estabelecimento de estratégias para o desenvolvimento local e regional. Por isso, as vantagens comparativas que essas localidades precisam construir se insere na perspectiva de que os territórios necessitam se engajar para competir mais e melhor, nas suas diferentes escalas, ao envolver o tecido social e o conhecimento produzido, assim como pro- movendo a cooperação e o aprendizado (BECKER, 2009).

Em vista do exposto, parece-nos claro que a ação dos Institutos Federais oportuniza uma formação que fornece subsídios à promoção do desenvolvimento de novas habilidades e competências dos beneficiados por esse vetor da política pública de Educação. Ao mesmo tempo, propicia-se, com essa formação, o incentivo à geração de inovações técnicas e tecnológicas, o que alargaria as possibilidades no desenvolvimento local e regional. Nessa medida, os agentes sociais locais e regionais precisam ter a habilidade de aproveitar os estoques de recursos locais, incluindo-se trabalhadores formados criticamente, com competências para gerar inovações e novos processos que agreguem valor à produtividade das empresas, organizações sociais, do Estado e do terceiro setor.

\section{Referências}

ABRUCIO, Fernando Luiz. A dinâmica federativa da educação brasileira: diagnóstico e propostas de aperfeiçoamento. OLIVEIRA, Romualdo P. SANTANA, Wagner. Educação e federalismo no Brasil: combater as desigualdades, garantir a diversidade. Brasília: UNESCO, 2010.

ALBAGLI, Sarita; MACIEL, Maria Lucia. Informação e conhecimento na inovação e no desenvolvimento local. Ci. Inf., Brasília, v. 33, n. 3, p.9-16, set./ dez, 2004. Disponível em: <http://www.scielo.br/scielo.php?script=sci_arttext\&pid=S0100-19652004000300002\&lng=en\&nrm=iso>. Acesso em: 10 abril 2019.

ALBUQUERQUE, Francisco. El enfoque del desarollo económico local. Cuaderno de Capacitación, n. 1, Serie: Desarrollo Económico Local y Emplabilidad Programa AREA - OIT em Argentina - Italia Lavoro. Buenos Aires: Organización Internacional del Trabajo, 2004. Disponível em: <http://www.flacsoandes.edu.ec/sites/default/files/agora/files/1251776298.area_enfoque_del_0.pdf $\geq$. Acesso em: 11 abril 2019.

AMARAL FILHO, J. A endogeneização no desenvolvimento local e regional. Planejamento e Políticas Públicas-PPP, IPEA, Brasília, 2001.

BARZOTTO, Luis F. Justiça social - gênese, estrutura e aplicação de um conceito. Revista Jurídica da Presidência, v. 5, n. 48, 2003. 21 p.

BECKER, Bertha K. O governo do território em questão: uma perspectiva a partir do Brasil. Parc. Estrat. Brasília: v. 14, n. $28,2009$.

COX, K.R. Globalization and the politics of local and regional development: the question of convergence. Transactions of the Institute of British Geographers, v. 29, n. 2, jun. 2004. pp. 179-194.

CRUZ, Rosana E. Pacto federativo e financiamento da educação: a função supletiva e redistributiva da União - o FNDE em destaque. Tese (Doutorado). São Paulo: USP, 2009. $434 \mathrm{f}$.

DIAS, Reinaldo; MATOS, Fernanda. Políticas públicas: princípios, propósitos e processos. São Paulo: Editora Atlas, 2012.252 p.

DINIZ, Clélio Campolina. Globalização, escalas territoriais e política tecnológica regionalizada no Brasil. Belo Horizonte: UFMG/Cedeplar, 2001.

IBAÑEZ, Pablo. Geografia e Inovação: uma abordagem urgente. Espaço Aberto, PPGG - UFRJ. V.4, n. 1, p. 131-138, 2014.

FERRÃO, João. Inovar para desenvolver: o conceito de gestão de trajectórias territoriais de inovação. Revista Internacional de Desenvolvimento Local (Interações). Campo Grande, v. 3, n. 4, p. 17-26, mar. 2002.

FRANÇA, C. L. de; CALDAS, E.de L. ;VAZ, J. C. (Org.). Aspectos econômicos de experiências de desenvolvimento local: um olhar sobre a articulação de atores. São Paulo: Instituto Pólis, 2004. (Publicações Pólis, 46). Disponível em: < http://www.polis.org.br/uploads/1005/1005.pdf >. Acesso em: 11 fev. 2019.

LIMONAD, Ester. Questões ambientais e o desenvolvimento local e Regional: de volta à região. Anais do X Encontro de Geógrafos da América Latina. São Paulo, 2005. p. 7853-7866.

Em busca do paraíso: algumas considerações sobre o desenvolvimento. Revista Brasileira de Estudos Urbanos e Regionais. Recife, v.15, n.1, p. 125-138, maio 2013

OIT - Organização Internacional do Trabalho. Local Development and Decent Work Resource Kit. Manila, International Labour Office, 2006. Disponível em: < https://www.ilo.org/wcmsp5/groups/public/---ed_emp/---emp_ent/documents/instructionalmaterial/wcms_112255.pdf>. Acesso em 28 abr. 2019.

PACHECO, Eliezer. Os Institutos Federais: uma revolução na educação profissional e tecnológica. PACHECO, Eliezer (org.). Os Institutos Federais: uma revolução na educação profissional e tecnológica. São Paulo: Moderna, 2011. 
PROGRAMA DAS NAÇÕES UNIDAS PARA O DESENVOLVIMENTO -PNUD. Relatório sobre o Desenvolvimento Humano no Brasil. Rio de Janeiro: IPEA/ PNUD, 1996.

PIRES DO RIO, Gisela. A espacialidade da economia: superfícies, fluxos e redes. CASTRO, Iná Elias de.; GOMES, Paulo Cesar C.; CORRÊA, Roberto Lobato. (Orgs.). Olhares geográficos: modos de ver e viver o espaço. Rio de Janeiro: Bertrand Brasil, 2012.

RÜCKERT, A. A. Reforma do Estado, reestruturações territoriais, desenvolvimento e novas territorialidades. I Seminário Nacional sobre Múltiplas Territorialidades. Porto Alegre; Canoas: Programa de Pós-Graduação em Geografia-Ufrgs; Curso de Geografia, Ibra, 2004.

O processo de reforma do Estado e a Política Nacional de Ordenamento Territorial. BRASIL. Para pensar uma Política Nacional de Ordenamento Territorial. Brasília: Ministério da Integração Nacional, p. 31-39, 2005.

RODRIGUES, Maria Cecília Prates. 0 índice do desenvolvimento humano (IDH) da ONU. Revista Conjuntura Econômica, v. 47, n. 7, Rio de Janeiro, julho 1993.

SEN, Amartya. Desenvolvimento como liberdade. Trad. de Laura Teixeira Motta; revisão técnica Ricardo Doninelli Mendes. São Paulo: Companhia das Letras, 2010.

SILVA, Augusto Cesar Pinheiro. Em busca do rural moderno no Estado do Rio de Janeiro: projetos, estratégias e gestão do território, exemplificados no norte e noroeste fluminense. Tese (Doutorado). Rio de Janeiro, 2005. $241 \mathrm{p}$.

SOUZA, Marcelo Lopes. Os conceitos fundamentais da pesquisa sócio-espacial. Rio de Janeiro: 2013. 319 p.

SOUZA, Mauro Sergio. P. S. Os Institutos Federais de Educação, Ciência e Tecnologia como vetores de desenvolvimento territorial no estado do Rio de Janeiro. Dissertação (Mestrado). Niterói, 2016. 233 p.

SOUZA, Nali de Jesus de. Desenvolvimento econômico. São Paulo: Atlas, 1993.

ULTRAMARI, Clovis; DUARTE, Fábio. Desenvolvimento local e regional. Curitiba: InterSaberes, $1^{\text {a }}$ ed., 2012. 152 p.

VARGAS, M. A. Aspectos conceituais e metodológicos na análise de arranjos e sistemas produtivos e inovativos locais. Programa de Pesquisa Micro e Pequenas Empresas em Arranjos Produtivos Locais no Brasil. Rio de Janeiro: IE/UFRJ, 2002.

VÁZQUEZ-BÁRQUERO, A. Endogenous Development: networking, innovation, institutions and cities. Nova lorque: Routledge, 2002.

La política de desarrollo económico local. AGHÓN, Gabriel; ALBUQUERQUE, Francisco; CÓRTES, Patricia. Desarrollo económico local y descentralización en América Latina: un análisis comparativo. Santiago do Chile: CEPAL/GTZ, p. 21-45, 2001.

WRIGHT, P. L; KROLL, Mark J; PARNELL, J. Administração estratégica: conceitos. 1 ed. 10 reimpr. São Paulo: Atlas, 2009.

BRASIL. Lei n011.892. Brasília, dezembro, 2008. 